\title{
Mobility and accessibility paradigms in Dutch policies: An empirical analysis
}

\author{
Ruben Akse \\ Radboud University Nijmegen \\ Ruben.akse@ru.nl
}

\section{Karst Geurs}

University of Twente

k.t.geurs@utwente.nl

\author{
Tom Thomas \\ University of Twente \\ t.thomas@utwente.nl
}

\begin{abstract}
To promote sustainable urban development, transport policies need to change from a car-oriented mobility planning paradigm to an accessibility-based paradigm, integrating land-use and transport policies. This paper uses the concept of planning paradigms to describe the current status of municipal transport planning and problem framing. The dominant transport planning paradigm of 172 Dutch municipalities is determined, based on a conceptual framework with 24 mobility and accessibility planning criteria. Statistical analysis is then conducted to find linkages between the planning paradigm and transport, landuse, and institutional characteristics of the municipalities. We show that the mobility planning paradigm still dominates Dutch municipal transport planning, and the accessibility planning paradigm is mostly found in large cities and highly urban municipalities. However, we do find indications of slow change in the transport planning paradigms in Dutch municipalities, as older policy documents are more (car) mobility focused than newer policy documents. Further research is necessary to examine the evolution of the paradigm shift in municipal transport planning over time and what factors promote the realization of such a paradigm shift.
\end{abstract}

\section{Article history:}

Received: September 20, 2021

Accepted: October 16, 2021

Available online: December 6, 2021

\section{$1 \quad$ Introduction}

Transport policies combine social sciences and civil engineering by presenting a narrative for social problems and socio-technical solutions, examining the production and use of vehicles such as cars, trains or bikes, embedding this in social practices, and linking it with political ambitions (Kanger et al., 2019). Since the mid-20th century, transportation planning and evaluation have focused on the mobility framework where an increase in mobility is an increase in territory that can be reached for a given investment of time and money. Faster movements, particularly by cars, were treated as the central goal (Levine et al., 2019). When evaluating the performance of a transportation system, the fundamental criterion for success has long been faster vehicle operating speed and common indicators include delay per capita, vehicle hours or money wasted while waiting in traffic and highway level of service (Levine et al., 2012). These metrics are not simply after-the-fact assessments but also used proactively to guide

Copyright 2021 Ruben Akse, Tom Thomas \& Karst Geurs

http://dx.doi.org/10.5198/jtlu.2021.2097

ISSN: 1938-7849| Licensed under the Creative Commons Attribution - Noncommercial License 4.0

The Journal of Transport and Land Use is the official journal of the World Society for Transport and Land Use (WSTLUR) and is published and sponsored by the University of Minnesota Center for Transportation Studies. This paper is also published with additional sponsorship from WSTLUR. 
policy towards transport investments and land-use regulation (Levine et al., 2019). Specifically, travel time savings are the dominant benefit category in ex-ante social cost-benefit analysis (CBA) of road investments used as an instrument to calculate whether a proposed investment is worth the costs or not, given certain benefits (Annema et al., 2007). Furthermore, transport policies on for example road safety and sustainability were developed later on, subordinate to the goals of flow and speed (Norton, 2015; Schwanen et al., 2011).

Different planning conceptions have been developed in academia and other knowledge institutions as a response to societal problems like unjust transport systems and high $\mathrm{CO} 2$ emission levels. Many scholars have proposed moving away from the mobility-based framework to an accessibility-based framework (Banister, 2011; Cervero, 1997; Ferreira et al., 2012; Geurs et al., 2010; Levine et al., 2019; Levine et al., 2012; Litman, 2013). The framework of accessibility differs from the mobility framework. Physical accessibility refers to the potential for travelling to actual destinations, and an increase in accessibility is an increase in the destinations that can be reached for a given investment in time and money. Focusing on accessibility challenges what is often considered to be a transport problem in the first place as well as what a suitable solution is. The concept of accessibility also focuses on how mobility is integrated in the urban area, including land-use aspects and the social dimensions of transport (e.g., equity, social exclusion). This also implies that accessibility is inherently multidimensional and more complex than mobility-based metrics (Levine et al., 2019).

Academics and other knowledge organizations create new accessibility tools and models as well as generating knowledge on relatively new concepts like just transport (see e.g., Martens, 2017). However, communicating this knowledge effectively with policy makers in the field remains a challenge for researchers. Several studies based on surveys among practitioners show the gap between the knowledge of the concept of accessibility and its utilization by land-use and transportation practitioners in developed countries across the globe (Boisjoly \& El-Geneidy, 2017; Papa et al., 2015). However, the studies do show that some planners are using accessibility thinking, indicators and models in their planning practice. Understanding the circumstances which stimulate governments to transition from mobility to accessibility goals and policies is important in order to enable future change regarding equity and sustainability.

In this paper, we use the concept of planning paradigms to describe the current status of municipalities regarding policy choice and problem framing in transport policy making. A planning paradigm is defined as a coherent way of conceptualizing and intervening in the transport system by policy makers. Issues mentioned in transport policy plans have a historical, an organizational and a social context which influence why and how problems and their possible solutions are described. These contexts become socially and institutionally embedded in paradigms which implicitly and/or explicitly shape policy choices, which help framing problems and their solutions, and which become visible in urban transport plans. The creation and upholding of these paradigms is a messy process, contrary to the classic linear policy cycle view of policy making. Many definitions describe a paradigm as a set of cognitive beliefs that are based on shared rules and standards (Kuhn, 1962), but offer a limited conceptualization of paradigms in a practical context like transport planning. There is therefore a large research gap in the analysis of planning paradigms beyond theory and their application in an empirical context. It is often unclear how the term paradigm can be translated into practical planning terms because of its lack of proper definition by researchers. Few papers have examined paradigms and policies in a transport planning context. In one example, Harms et al. (2015) concluded that improving the organization and implementation of cycling policies had a positive effect on the effectiveness of Dutch cycling policies.

The aim of the research presented in this paper is twofold. Firstly, we operationalize the paradigm concept by developing criteria that enable the quantification of the outcome of the policy-making process. Secondly, we conduct a large-scale policy analysis of Dutch municipal transport policies to examine 
the conditions relevant for paradigmatic policy change.

The outline of this paper is as follows. Firstly, Section 2 presents the theoretical framework with an analysis of the history of planning paradigms and an operationalization of the paradigm concept for planning practices. The methodology of how to study planning paradigms in practice will then be explained in Section 3, namely by extensive empirical analysis of Dutch municipal policy documents. The results of this analysis is presented in Section 4, and the conclusions in Section 5. Finally, discussion points and future research possibilities will be elaborated on in Section 6.

\section{Theoretical framework}

\subsection{Operationalizing the paradigm concept}

An operationalization of the paradigm concept for a policy context needs more than the original definition given by Kuhn (1962), which approaches a paradigm as a set of cognitive beliefs that are based on shared rules and standards. Likewise, the political economist Hall (1993) defines policy paradigms as interpretive frameworks 'that specify not only the goals of policy and instruments that can be used to attain them, but also the very nature of the problems they are meant to be addressing' (Hall, 1993, p. 279). It is often unclear what the term paradigm means in a practical planning context because of its lack of proper definition by researchers. In the literature, many transport and geography researchers have advocated moving from one paradigm to another. For example, Cervero (1997) advocated moving from a mobility planning paradigm to an accessibility planning paradigm. Banister (2008) suggested moving towards a sustainable mobility paradigm without defining what a paradigm exactly is. More recently, Lyons (2018) aimed to align 'the smart' and 'the sustainable' planning paradigm with each other. With all the authors the definition of the paradigm relates to the adjective that is placed before the word, which makes the paradigm concept itself fuzzy in a planning context. Jones (2014) tried to define a transport planning paradigm by directly applying the Kuhnian (scientific) definition of a paradigm into a planning context. Another issue is that Jones' (2012) idea of a paradigm, as with other authors, is only dealt with in term of ideas and not in terms of activities. Paradigms are not only composed of knowledge or beliefs, but also activities such as acquiring and using a set of skills in a specific context (Rouse, 2003; Schwanen et al., 2011). A planning paradigm has to be supported by planners and scientists and is embodied by the choice of certain policy instruments and technological modelling instruments, like traffic models and GIS-based maps. We therefore define a planning paradigm using the original cognitive (idea) foundation, consisting of both (philosophical) assumptions (1) and policy goals (2). Equally important is the action-based part of paradigms: elements that indicate actual choices of policy practices. This part consists of policy instruments (3), and evaluative criteria (4) on which choices have to be based. We refer here to instruments as both methodologies that enable the measurement of the performance of the transport system and the concrete policy choices regarding intervention in the transport system. The embodiment of paradigms through instruments also means that the evaluation criteria of a system are important, as such criteria embody the application of the paradigmatic beliefs in practice.

By integrating literature on cognitive elements and action-based elements of a paradigm as described above, a conceptual model for assessing mobility and accessibility planning paradigms in transport policy documents was developed (Figure 1). It shows that the planning paradigm consists of a cognitive basis including (philosophical) assumptions and policy goals, and action-based practices including policy instruments and evaluative measures. The table illustrates each element of the paradigm for two specific examples analyzed in this paper, namely mobility and accessibility planning criteria (see Section 2.2). Variables that are relevant for explaining the presence of planning paradigms can be divided into three groups: institutional variables, transport variables and land-use variables (see Section 2.3 for supporting literature). 


\begin{tabular}{|c|c|c|c|}
\hline \multicolumn{2}{|c|}{ Elements } & Mobility planning criteria & Accessibility planning criteria \\
\hline \multirow{2}{*}{ 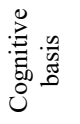 } & $\begin{array}{l}\text { (Philosophical) } \\
\text { assumptions }\end{array}$ & Network efficiency & Traveling as part of urban system \\
\hline & Policy goals & Travel-time reduction & Liveable and sustainable urban places \\
\hline \multirow{2}{*}{ 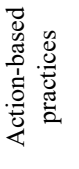 } & $\begin{array}{l}\text { Policy } \\
\text { instruments }\end{array}$ & Car infrastructure & $\begin{array}{l}\text { Infrastructure for sustainable modes and } \\
\text { non-infrastructural measures }\end{array}$ \\
\hline & $\begin{array}{l}\text { Evaluative } \\
\text { measures }\end{array}$ & Time-based thresholds & Location-based measures \\
\hline
\end{tabular}

Figure 1. Conceptual model for assessing mobility and accessibility planning paradigms in transport policy documents

\subsection{Indicators for a planning paradigm in a transport context}

There are many possibilities for specifying different planning paradigms in a transport context, but we have focused on mobility and accessibility in an urban context as two planning lenses that are relevant for both the literature and for analyzing planning practices. In order to operationalize both terms, we propose different criteria that are relevant for each of the four elements of a planning paradigm. The mobility planning paradigm represents a sectoral transport-based perspective, which looks at efficient ways of moving people and goods, so that travelers minimize their travel time (Banister, 2008). Criteria that embody this planning paradigm focus broadly on network efficiency (assumption), travel time reduction (goal), the infrastructural car network (policy instrument) and time-based thresholds (evaluative criterion), see Jensen (2015). The accessibility planning paradigm regards transport planning as part of urban planning, resulting in land-use, sustainability and social problems also becoming concerns of the transport planner. This broad perspective of how accessibility should be applied in a planning context is based on the idea that transport flows, the urban streets and public spaces are interconnected (von Schönfeld \& Bertolini, 2017). Criteria that embody this planning paradigm focus on travel as part of a social urban system (assumption, livable and sustainable urban places (goal), infrastructure for sustainable modes, as well as including non-infrastructural measures like land-use developments (instruments) and location-based measures (evaluative criterion). A further concretization of these criteria is given in the methodology section.

\subsection{Variables for explaining presence of planning paradigms}

For empirical analysis, it is important to know which variables might be relevant for explaining the presence of planning paradigms. Literature has shown that the mobility planning paradigm has become dominant due to institutional reasons. The institutional embedding of a planning paradigm through groups of actors, rules and practices has been essential for sustaining a planning culture in an organizational context, as Geels (2012) and Van Der Brugge et al. (2005) demonstrated with a multi-level perspective analysis of decarbonizing the transport system and of restructuring Dutch water policies. They showed that policy makers rely on (political) values such as a (dis)belief in freedom, rationality or logic, originating from different educational backgrounds and personal preferences. In the European 
context, Koglin (2015a, 2015b) compared the planning doctrine of the cities of Stockholm and Copenhagen with each other and showed that organization and political values mattered for cycling planning. Through an analysis of sustainable bicycle policies in Copenhagen and Beijing, it was concluded that 'the efficiency of bicycle infrastructure planning corresponds to the level of planning knowledge and experience gained, shared and embedded in the local planning culture' (Zhao et al., 2018, p. 158). However, all these studies remain limited to a comparison of the different planning approaches of a few (international) cities.

A number of studies have highlighted organizational and institutional barriers towards the use of accessibility planning instruments (Boisjoly \& El-Geneidy, 2017; Geurs \& Levine, 2015; Te Brömmelstroet et al., 2014). This confirms the idea that a distinction between a cognitive and action-based part of a planning paradigm is relevant. All in all, local organizations are important for maintaining and implementing planning paradigms, as well as politicians who decide over the funding and future directions of transport policy making (Stone, 2013). In addition, informal networks are also deemed important for sharing policy knowledge (Marsden et al., 2011). This means that the network of civil servants with external actors such as consultants can be relevant for the establishment of planning paradigms (Tennøy et al., 2016).

Apart from institutional variables, general municipal variables like transport-related variables and land-use variables could correlate with paradigm scores. Modal split, connected with the level of negative externalities could be a reason to adopt certain sustainable transport policies or adjust road configurations (May, 2012; Stopher \& Stanley, 2014; van Wee et al., 2013). Another very important negative externality is traffic safety (Wegman, 2013). In 2019, the number of traffic fatalities was 661 in the Netherlands (SWOV, 2020). This could be a reason to introduce specific types of transport policies. Social problems related to transport such as social exclusion lead to unjust transport systems (Martens, 2017), which could lead to pressure for transport policy interventions based on equity. Land-use characteristics like sociodemographics (such as age and educational level) influence travel behavior (Dijst et al., 2013), and can impact policy choices. Land-use characteristics such as the level of urbanity and recently published numbers on density and functional mix use (Harbers et al., 2019) could explain the rationale for a greater or lesser focus on car infrastructure or public transport in policy making.

\section{$3 \quad$ Methodology and data}

\subsection{Selection of transport policy documents}

In order to study transport planning paradigms in the planning practice, a large-scale policy analysis of Dutch municipal transport policies was conducted. By law, each Dutch municipality has to provide a coherent framework for its transport policies. ${ }^{1}$ The availability of an up-to-date municipal transport policy document was examined for all medium-sized and large urban municipalities in the Netherlands. Policy plans were found either by searching on municipal websites or contacting local clerks. The selection included 210 (out of 355) municipalities which had either a population larger than 30,000 or population density higher than 1000 inhabitants $/ \mathrm{km}^{2}$. In addition, some smaller and urban municipalities well connected by the railway network were added by scanning the list of municipalities, based on our personal knowledge of the Dutch urban system. A significant number of the selected municipalities (38 municipalities) either did not have an up-to-date transport policy document or were renewing it. Over

\footnotetext{
${ }^{1}$ See 'Planwet Verkeer en Vervoer' Par. 4 Art. 8-10, https://wetten.overheid.nl/BWBR0009642/2015-01-01\#Opschrift Note that this law will be replaced by a new Dutch Environmental and Planning Act in 2022, which will integrate all spatial planning and transport planning rules into one regulatory framework.
} 
172 Dutch municipal transport policy documents were included in the analysis, a sample of about $50 \%$ of all municipalities in the Netherlands, comprising about $75 \%$ of the Dutch population (around 12.5 million). Furthermore, additional variables to characterize the municipalities were collected as input for a statistical analysis. The diversity of municipalities in terms of political orientation, socio-demographic characteristics and size enabled an analysis of the relations between the present planning paradigm and municipal characteristics.

\subsection{Analysis of transport policy documents}

A transport planning paradigm was operationalized through reading and scoring policy documents based on criteria that described the (philosophical) assumptions, goals, policy instruments and evaluative elements of an urban policy plan. Concrete criteria were defined based on literature on mobility and accessibility paradigms (see Section 2.2), and indicators on parking policies and bypasses were added after having read a first sample of policy documents, as well as making a distinction between travel time minimization and reliability. A policy plan should be regarded as an outcome of the paradigm-based process of policy making, in the form of specific policy content. Apart from the document content, secondary information was gathered by looking at the context in which a document was created. This included the year of publication, guiding consultancy, and type of document (e.g., vision or classic traffic design plan).

Policy documents were each read and cross-compared in small groups by the main author. Points were consequently assigned according to elements of each of the planning paradigms. If none of the criteria were mentioned in the policy document, zero points were assigned for that criterion. The analysis was compared with a student's review for a smaller set of municipalities, and no large differences were detected. All specified criteria for the mobility planning paradigm are displayed in Table 1. The (philosophical) assumptions included network efficiency and promoting speed, or more generally a focus on mobility growth. Policy goals included reliability and a general reduction in travel time, as transport characteristics are the lens here for proposing policy goals with the aim of improving (economic) efficiency. As for policy instruments, the focus was on (road) network infrastructure, from a general increase in road capacity to adjustments of junctions and the development of more highway connections. Also, parking policies conforming to car mobility growth were labeled as a criterion. The evaluative measure was based on network characteristics like travel time thresholds and IC ratios.

All specified criteria for the accessibility planning paradigm are displayed in Table 2 . The assumptions focused on a broader perspective for transport, integrated into an urban system. This translated into concrete criteria regarding the social aspects of travel (possibilities) including the social justness of a transport system (e.g., equity issues). Goals were about promoting livable and urban places, where transport was sustainable, equal and safe. Policy instruments focused on providing infrastructure for sustainable modes as well as non-infrastructural measures like land-use and behavioral measures. Particular attention was paid to accessibility for lower-income areas and specific measures for urban livability. The evaluative measure was based on the number of destinations that could be reached by (different types of) citizens. 
Table 1. Specified criteria for mobility planning paradigm

\begin{tabular}{|c|c|c|c|}
\hline & Type of aspect & Specific criterion & Points if mentioned \\
\hline \multirow{6}{*}{ 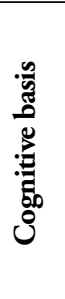 } & \multirow{3}{*}{ (Philosophical) Assumptions } & Efficiency and speed & 1 \\
\hline & & Facilitating (car) mobility growth & 1 \\
\hline & & Travel as disutility or derived demand & 1 \\
\hline & \multirow{3}{*}{ Policy goals } & General travel time reduction (throughput) & 1 \\
\hline & & Travel time reliability & 1 \\
\hline & & Improving economic growth & 1 \\
\hline \multirow{6}{*}{ 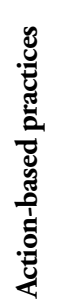 } & \multirow{5}{*}{ Policy instruments } & Increasing existing road capacity for cars & 1 \\
\hline & & Hierarchy of roads (flow/neighborhood) & 1 \\
\hline & & Adjustments to junctions (roundabouts/traffic lights) & 1 \\
\hline & & Development of bypasses and highway connections & 1 \\
\hline & & Demand-driven parking policies & 1 \\
\hline & Evaluative measure & Infrastructure-based (e.g., time thresholds/IC ratios) & 1 \\
\hline
\end{tabular}

Table 2. Criteria for evaluating the accessibility planning paradigm

\begin{tabular}{|c|c|c|c|}
\hline & Type of aspect & Specific criterion & Points if mentioned \\
\hline \multirow{6}{*}{ 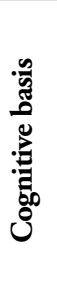 } & \multirow{3}{*}{ (Philosophical) Assumptions } & Travel as increasing possibilities of citizens & 1 \\
\hline & & Political meaning of traveling: employ activities & 1 \\
\hline & & Justness of transport system & 1 \\
\hline & \multirow{3}{*}{ Policy goals } & Promoting urban livability and sustainability & 1 \\
\hline & & Social (equity) issues & 1 \\
\hline & & Traffic safety & 1 \\
\hline \multirow{6}{*}{ 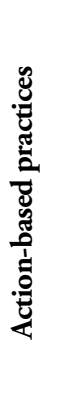 } & \multirow{5}{*}{ Policy instruments } & $\begin{array}{l}\text { Providing physical infrastructure for bicycles and } \\
\text { public transport }\end{array}$ & 1 \\
\hline & & Integrated land-use policies & 1 \\
\hline & & $\begin{array}{l}\text { Behavioral measures (Information provision, market- } \\
\text { ing) }\end{array}$ & 1 \\
\hline & & Attention for lower incomes (in specific areas) & 1 \\
\hline & & $\begin{array}{l}\text { Specific measures for promoting livability (e.g., envi- } \\
\text { ronmental zone or electric charging poles) }\end{array}$ & 1 \\
\hline & Evaluative measure & Location-based (e.g., integral/accessibility-focused) & 1 \\
\hline
\end{tabular}

Based on the total scores for each of the paradigms, a balanced score was calculated by subtracting the score for the mobility planning paradigm from the accessibility planning paradigm. In total, 12 points could be assigned for each paradigm. This meant that the total range of balanced scores lay between -12 and +12 . The balanced score showed which type of paradigm was dominant in a municipality.

\subsection{Secondary data collection}

To analyze the characteristics of municipalities with a mobility or accessibility planning paradigm, a descriptive statistical analysis was carried out. Three categories of variables were distinguished as described 
in the theoretical framework (see section 2.2), namely transport-related characteristics, land-use and population characteristics and institutional characteristics. These categories allowed us to characterize different parts of the transport system that were relevant for the paradigm-based process of policy making.

Firstly, transport-related characteristics (such as modal split, kilometers travelled, emission levels, accident rates) were hypothesized to be related to policy goals concerning traffic flow, sustainability and traffic safety. It was hypothesized that the policy plans of municipalities with relatively high car use, emissions and accidents would be more likely to show mobility planning paradigms. Secondly, land-use characteristics (such as population density, land-use mixing, type of train stations present) and population characteristics (such as age, education level) were also hypothesized to affect the planning paradigm. It was also expected that larger or highly urban municipalities would lean towards an accessibility planning paradigm. Thirdly, institutional characteristics could relate to the context in which the policy document was created. It was expected that more recent documents would be more progressive, and that a higher share of progressive or left-wing votes would correlate with higher scores on the accessibility planning paradigm. Note that, for practical reasons, this paper did not include voter shares of local municipal parties in municipal elections. Unlike the USA or UK, the Netherlands has a multiparty system, originating in historic divisions between Catholics, Protestants, Socialists and Liberals (Van Wijk, 2019). Generally, classic right parties are in favor of facilitating car-mobility growth, whereas more progressive parties tend to inhibit car mobility growth, see for example Smaal (2012, pp. 799800). Moreover, it was hypothesized that having external consultancy in the municipal transport policy development process would lead to adopting less mobility-based policy goals, as social learning would be stimulated. Please note we also tested two accessibility metrics (number of jobs within 45 minutes by car and public transport) available from earlier work (Pritchard et al., 2019). However, both metrics were excluded as they were highly correlated with variables (e.g., density, urbanity levels and NO2 emissions) in did not increase explanatory power of principal component analysis and regression analysis.

The last column of Table 3 indicates the expected effect of each variable on the balanced score, where a minus stands for the mobility planning paradigm and a plus for the accessibility planning paradigm. Furthermore, the municipal scores were divided into four clusters, based on the median values of the mobility and accessibility scores. Then, different variables as shown in Table 3 were tested for statistical difference for each of the four clusters. 
Table 3. Variables on municipal level that have been used for descriptive analysis

\begin{tabular}{|c|c|c|c|}
\hline & Variable & Source & $\begin{array}{l}\text { Expectation for } \\
\text { balance score }\end{array}$ \\
\hline \multirow{9}{*}{$\begin{array}{l}\text { Variable category 1: } \\
\text { Transport-related variables }\end{array}$} & Car ownership per household & $\mathrm{CBS}^{1}$ & - \\
\hline & Modal split (\% of trips) & CBS & Car - ; Train/Bike + \\
\hline & Modal split (\% of kilometers) & CBS & Car - ; Train/Bike + \\
\hline & Average kilometers travelled per day & CBS & - \\
\hline & PM10 concentration & RIVM $^{2}$ & + \\
\hline & $\mathrm{NO}_{\mathrm{x}}$ concentration & RIVM & + \\
\hline & $\begin{array}{l}\mathrm{CO}_{2} \text { emissions } / 1,000 \text { inhabitants (without } \\
\text { highways) }\end{array}$ & RIVM & + \\
\hline & $\begin{array}{l}\text { Traffic injuries/1,000 inhabitants (10-year } \\
\text { average) }\end{array}$ & SWOV $^{3}$ & + \\
\hline & $\begin{array}{l}\text { Traffic death/100,000 inhabitants ( } 5 \text { year } \\
\text { cumulative) }\end{array}$ & SWOV & + \\
\hline \multirow{12}{*}{$\begin{array}{l}\text { Variable category 2: } \\
\text { Land use and population } \\
\text { variables }\end{array}$} & Population size & CBS & + \\
\hline & Density & CBS & + \\
\hline & Floor-space index & CBS & + \\
\hline & Mixed-used index & CBS & + \\
\hline & Urbanity level (address density/km2) & CBS & + \\
\hline & Train station type & $\begin{array}{l}\text { Prorail4/Own } \\
\text { analysis }\end{array}$ & Small - ; High + \\
\hline & Age groups (\%) & CBS & Young +; Old - \\
\hline & Educational levels (\%) & CBS & Low - ; High + \\
\hline & \% low-income households & CBS & + \\
\hline & $\begin{array}{l}\text { Inhabitants living and working in same } \\
\text { municipality (\%) }\end{array}$ & CBS & - \\
\hline & $\begin{array}{l}\text { Function-mixture index ( } 0 \text { only dwellings, } \\
100 \text { only working) per municipality }\end{array}$ & $\mathrm{PBL}^{5}$ & - \\
\hline & Number of students living in municipality & CBS & + \\
\hline \multirow{6}{*}{$\begin{array}{l}\text { Variable category } 3 \text { : } \\
\text { Institutional and organiza- } \\
\text { tional variables }\end{array}$} & Share of political parties & $\begin{array}{l}\text { Own analysis ( } 2017 \\
\text { national elections) }\end{array}$ & $\begin{array}{l}\text { Conservative - ; } \\
\text { Progressive + }\end{array}$ \\
\hline & Sustainability ambitions & $\mathrm{VNG}^{6}$ questionnaire & + \\
\hline & Solvability ratio & CBS & - \\
\hline & $\begin{array}{l}\text { External consultancy in development } \\
\text { process }\end{array}$ & Own analysis & + \\
\hline & Years since publication & Own analysis & - \\
\hline & GVVP/vision-based & Own analysis & $(-1+)$ \\
\hline
\end{tabular}

${ }^{1}$ Statistics Netherlands (CBS); ${ }^{2}$ National Institute of Public Health and the Environment (RIVM); ${ }^{3}$ Institute for Road Safety research (SWOV); ${ }^{4}$ National railway manager (Prorail), ${ }^{5}$ Netherlands Environmental Assessment Agency (PBL), ${ }^{6}$ Union of Dutch Municipalities (VNG).

\subsection{Statistical analysis}

Firstly, a Principal Component Analysis (PCA, using SPSS) was carried out to reduce the number of variables and to improve interpretability. In layman's terms, it means that variables which are linearly related with each other are combined in a so-called component, see e.g., Field (2009), for an elaborate 
explanation. These components represent the original data, but with less variables so that only the most relevant information is retained. The rotation methodology (i.e., how different components relate to each other) was orthogonal by choosing Varimax, after having tried the oblique rotation Oblimin as well. But, it appeared that correlations between components were small, therefore an orthogonal rotation was preferred for interpretation reasons. Each component was given a name, based on the characteristics of the individual variables and spatial GIS analyses. Secondly, a multiple linear regression was conducted to examine whether the different component scores were correlated with the paradigm scores. A regression uses multiple independent variables (in this case, components that represent all variables) to predict the dependent variable, namely the paradigm scores.

\section{$4 \quad$ Empirical results}

\subsection{Policy document characteristics}

The analyzed Dutch policy documents had the following characteristics. Most of the documents had a classic structure in the form of a so-called 'municipal transport plan' (or GVVP in Dutch), as indicated by national law. A small number however were written in the form of a mobility vision, structural vision or ambition document. A minority of all the documents was written in cooperation or supervision with an external consultant. Larger municipalities like Amsterdam and Den Haag had their own municipal consultant office, effectively acting as an external consultant. In terms of time, most of the documents were written between 2009 till 2020. 10 years is a commonly held threshold for writing a new document. There were outliers though of plans that were over 15 years old.

Table 4. Document-related statistics of municipal policy documents

\begin{tabular}{|ll|}
\hline Total number of documents analyzed: $\mathrm{N}=172$ & \\
\hline Municipal Transport Plan (GVVP): & Vision-based document: \\
$60 \%(103 / 172)$ & $40 \%(69 / 172)$ \\
\hline Consultant involved: & Consultant not involved: \\
$45 \%(78 / 172)$ & $55 \%(94 / 172)$ \\
\hline Age of plan in years (mean): 5.8 & \\
\hline Age of plan in years (median): 5 & \\
\hline Standard error of mean: 0.32 & \\
\hline
\end{tabular}

\subsection{Exploration of scores}

An overview of the scores for each of the two paradigms is displayed in Table 5. The balanced score was calculated by subtracting the mobility score from the accessibility score. The mobility mean lay substantially higher than the accessibility mean. Furthermore, only a small portion of municipal documents scored high, the majority scoring below six points. This effect could be seen even more clearly in the balanced scores, in which most municipalities scored negatively with a minority of policy documents scoring above zero. The range of balanced score lay between -9 and 7 , with a median of -3 . This means most urban municipalities in the Netherlands currently adopt the mobility planning paradigm in their policies. 
Table 5. General statistics of scores

\begin{tabular}{|lccc|}
\hline & Mobility planning score & Accessibility-planning score & Balanced score \\
\hline Mean & 6.8 & 4.2 & -2.6 \\
\hline Median & 7 & 4 & -3 \\
\hline Standard error of mean & 0.14 & 0.14 & 0.24 \\
\hline
\end{tabular}

When the scores of the mobility planning paradigm and accessibility planning paradigm were plotted against each other, it became clear that there is a moderate negative correlation of 0.41 between the two using Pearson's correlation coefficient. This meant that when a municipality scored relatively low on mobility, it could be expected that it scored relatively high on accessibility and the other way around. This relation can be seen in Figure 2, displayed based on the number of municipalities or the population size of municipalities. The difference between both figures indicates that frontrunner municipalities (i.e., scoring high on the accessibility planning paradigm and low on the mobility planning paradigm) had large populations, but were not large in number. Also some laggards (i.e., scoring low on the accessibility planning paradigm and high on the mobility planning paradigm) increased in population size.
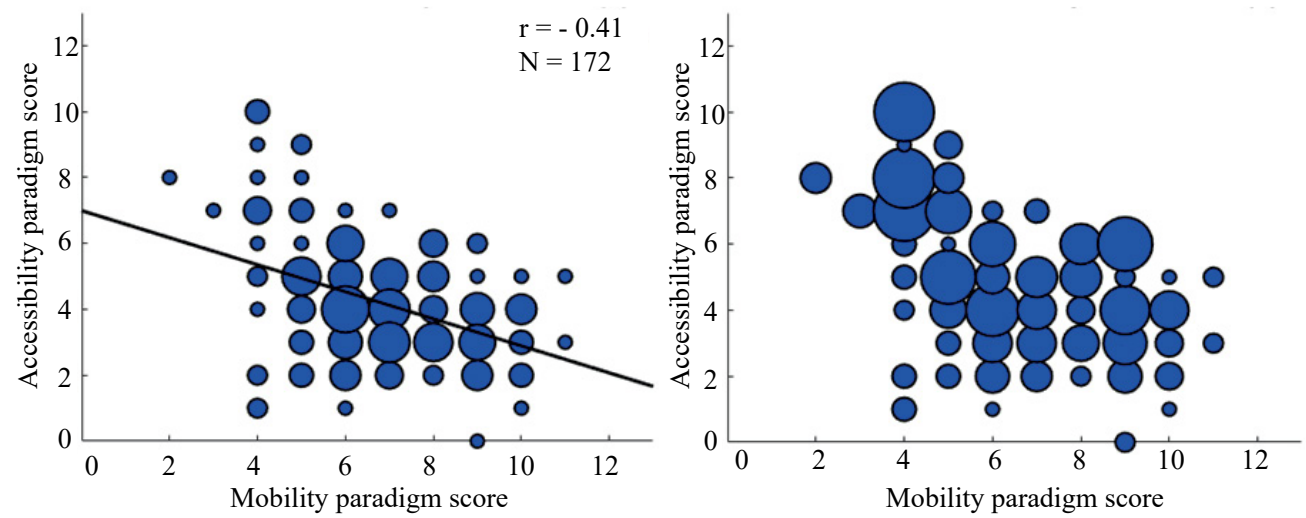

Figure 2. Scores policy documents with negative linear relationship $(r=-0.41, p<0.001)$; point size according to cumulative number of municipalities having that point combination (left) and point size according to cumulative population per point combination (right)

As for the geographical pattern (displayed in Figure 3) it became clear that large municipalities such as Amsterdam and Rotterdam scored higher than middle-sized municipalities. To recall, the balanced score is calculated by subtracting the mobility score from the accessibility score, representing the extent to which a municipality adopts progressive or conservative transport policies. Figure 3 also shows that higher balanced scores are better explained by the action-oriented part (Instruments and monitoring) than the cognitive basis of planning paradigms. This is confirmed by comparing the lower correlation between the total balanced score and the philosophical/goals balanced score $(r=0.84)$ and the total balanced score and the instruments/monitoring balanced score $(\mathrm{r}=0.94)$. There is a positive correlation of 0.59 between the balanced score of the cognitive elements and the balanced score of the action-based elements. 

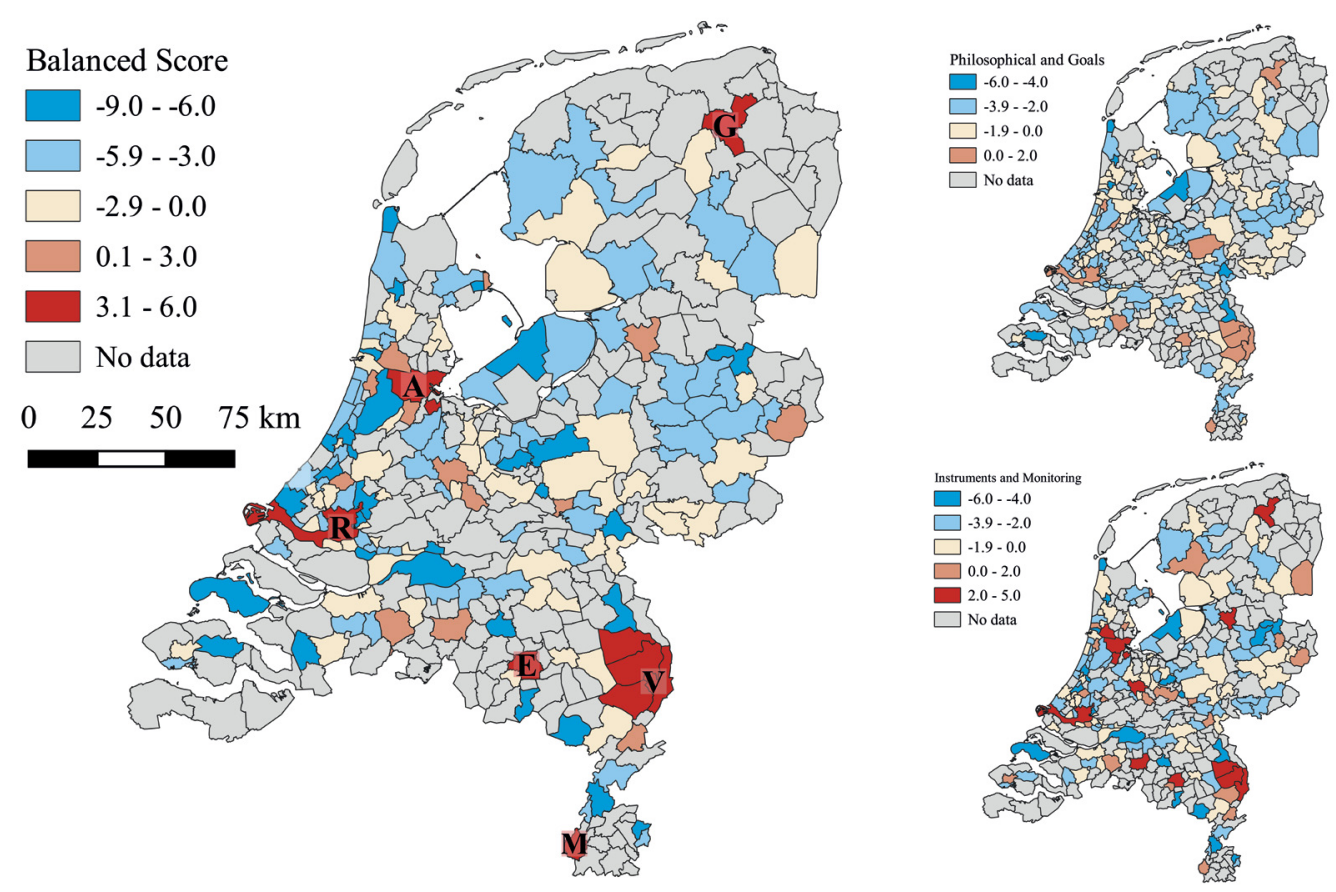

Figure 3. Left figure is balanced score for each analyzed policy document (QGIS Generated). Red (+) is accessibility-focused, whereas blue (-) is mobility-focused; upper right figure is the balanced score for (philosophical) assumptions and policy goals; below right figure is the score for policy instruments and monitoring. $G=$ Groningen, $A=$ Amsterdam, $R=$ Rotterdam, $E=$ Eindhoven, $V=$ Venlo (cooperation with Venray, Horst a/d Maas, Peel a/d Maas), $M=$ Maastricht

\subsection{Descriptive statistics}

In order to analyze characteristics of the municipalities, a descriptive statistical analysis was done to see which variables differed significantly. Each municipality was put into a cluster, based on the score of each paradigm. Four clusters were defined for interpretability reasons, based on the median values of the mobility planning paradigm score and the accessibility planning paradigm score. Practically, this meant that each cluster had score limits according to Table 6. Using an Anova1 test or Chi-square test (depending on the type of variable), only significant variables $(p<0.05)$ were used as input for the Principal Component Analysis. Most modal trip shares differed significantly for the four clusters, apart from cycling. This might be explained by the fact that cycling is so common in the Netherlands for all municipalities, that not much significant differences existed between the municipal clusters. $\mathrm{CO} 2$ and PM10 emissions due to traffic were slightly above the significant threshold, but NO2 emissions were significantly different. This seems plausible, as $\mathrm{CO} 2$ emissions are the highest for highways, which are quite evenly spread in the Netherlands, and PM10 emissions are also caused by industry and farming, which means that urban-related characteristics do not correlate uniformly. Statistics related to traffic safety did not differ significantly for each of the four clusters, against expectations. Almost all land-use variables differed for the four clusters. For the organizational variables, it stood out that the presence of an external consultant did not differ significantly for each of the four clusters. Furthermore, the sustainability ambitions as stated by the municipality through a questionnaire did not differ significantly as well as the financial state of the municipality, quantified through a simple solvability ratio. The political orientation of a municipality did differ significantly though. 
Table 6. Cluster division of scores, based on median values

\begin{tabular}{|lccc|}
\hline & Accessibility score & Mobility score & Characterization \\
\hline Cluster 1 & $>4$ & $<7$ & Frontrunners \\
\hline Cluster 2 & $>4$ & $\geq 7$ & Inbetweeners \\
\hline Cluster 3 & $\leq 4$ & $<7$ & Inbetweeners \\
\hline Cluster 4 & $\leq 4$ & $\geq 7$ & Laggards \\
\hline
\end{tabular}

Since many of the significant variables correlated with each other, a Principal Component Analysis (PCA) was carried out to reduce the number of variables and to improve interpretability. As the organizational variable category included nominal variables, this section was not selected for the PCA. 24 variables from the transport-related and land-use characteristics that significantly differed for the four clusters were used as input for the PCA. Based on the Eigenvalues $>1$ and scree plot, six components were included in the final solution. Eventually, the 6-component solution could explain $79.7 \%$ of the variance of the original solution. Each component was given a name, based on the characteristics of the individual variables. All component loadings larger than 0.4 are displayed in Table 7 . The components were labelled as:

- Component 1: Physical urban character ${ }^{2}$ (42.9\% explaining the variance)

- Component 2: Number of students (9.8\% explaining the variance)

- Component 3: Social urban character (8.9\% explaining the variance)

- Component 4: Car/public transport orientation (8.0\% explaining the variance)

- Component 5: Elderly citizens (5.5\% explaining the variance)

- Component 6: Educational level citizens (4.6\% explaining the variance)

\footnotetext{
${ }^{2}$ Urban character refers to specific characteristics of urban areas in terms of form, function and social use, that make an urban area is what it is.
} 
Table 7. Rotated component matrix PCA procedure (Varimax Rotation), only correlations $>0.4$ plotted

\begin{tabular}{|c|c|c|c|c|c|c|}
\hline Components $\rightarrow$ & \multirow{2}{*}{$\begin{array}{l}\text { 1: Physical } \\
\text { urban character }\end{array}$} & \multirow{2}{*}{$\begin{array}{l}\text { 2: Number of } \\
\text { students }\end{array}$} & \multirow{2}{*}{$\begin{array}{l}\text { 3: Social urban } \\
\text { character }\end{array}$} & \multirow{2}{*}{$\begin{array}{l}\text { 4: Car } / \mathrm{PT} \\
\text { orientation }\end{array}$} & \multirow{2}{*}{$\begin{array}{l}\text { 5: Elderly } \\
\text { citizens }\end{array}$} & \multirow{2}{*}{$\begin{array}{l}\text { 6: Educational } \\
\text { level }\end{array}$} \\
\hline Variables $\downarrow$ & & & & & & \\
\hline Density & 0.845 & & & & & \\
\hline FSI & 0.830 & & & & & \\
\hline $\mathrm{NO}_{2}$ concentration & 0.782 & & & & & \\
\hline Bus_tram_trips & 0.696 & & & & & \\
\hline Urbanity level & 0.668 & & & 0.410 & & \\
\hline Population_20_25 (\%) & & 0.871 & & & & \\
\hline Number of students (\%) & & 0.840 & & & & \\
\hline Population_45_65 & & -0.640 & & & -0.405 & \\
\hline Car possession & -0.455 & -0.540 & & -0.415 & & \\
\hline Low_income (\%) & & & 0.794 & & & \\
\hline Population size & & & 0.734 & & & \\
\hline $\begin{array}{l}\text { Living and working in } \\
\text { same municipality (\%) }\end{array}$ & & & 0.728 & & & \\
\hline Type_train_station & & & 0.599 & 0.539 & & \\
\hline Walk_trips & 0.477 & & 0.495 & & & \\
\hline Population_10_15 (\%) & & -0.444 & -0.482 & & 0.469 & \\
\hline Train_trips (\%) & & & & 0.857 & & \\
\hline Train_km (\%) & & & & 0.843 & & \\
\hline Car_driver_km (\%) & & & & -0.544 & & \\
\hline Car_driver_trips (\%) & & -0.464 & & -0.472 & & \\
\hline Population_80 (\%) & & & & & -0.859 & \\
\hline Population_65_80 (\%) & & & & & -0.814 & \\
\hline Population_25_45 (\%) & 0.434 & & 0.407 & & 0.585 & \\
\hline Education_low (\%) & & & & & & -0.882 \\
\hline Education_high (\%) & & & & & & 0.851 \\
\hline
\end{tabular}

\subsection{Transport-related and land-use characteristics}

Using the six components, component scores were added as a third dimension to the municipal policy document score plots. In this way, relevant urban characteristics are displayed directly with the paradigm scores in Figure 4. To improve interpretability the scores are not directly displayed but through a moving average, calculated by translating the scores with a 2-D convolution methodology using a kernel that is the sum of $50 \%$ of the original value and $50 \%$ equally distributed over the direct neighboring values ( $3 \times 3$ matrix). The convoluted (or averaged) result displays the general trend of the component scores better, at the expense of reading individual outliers. 

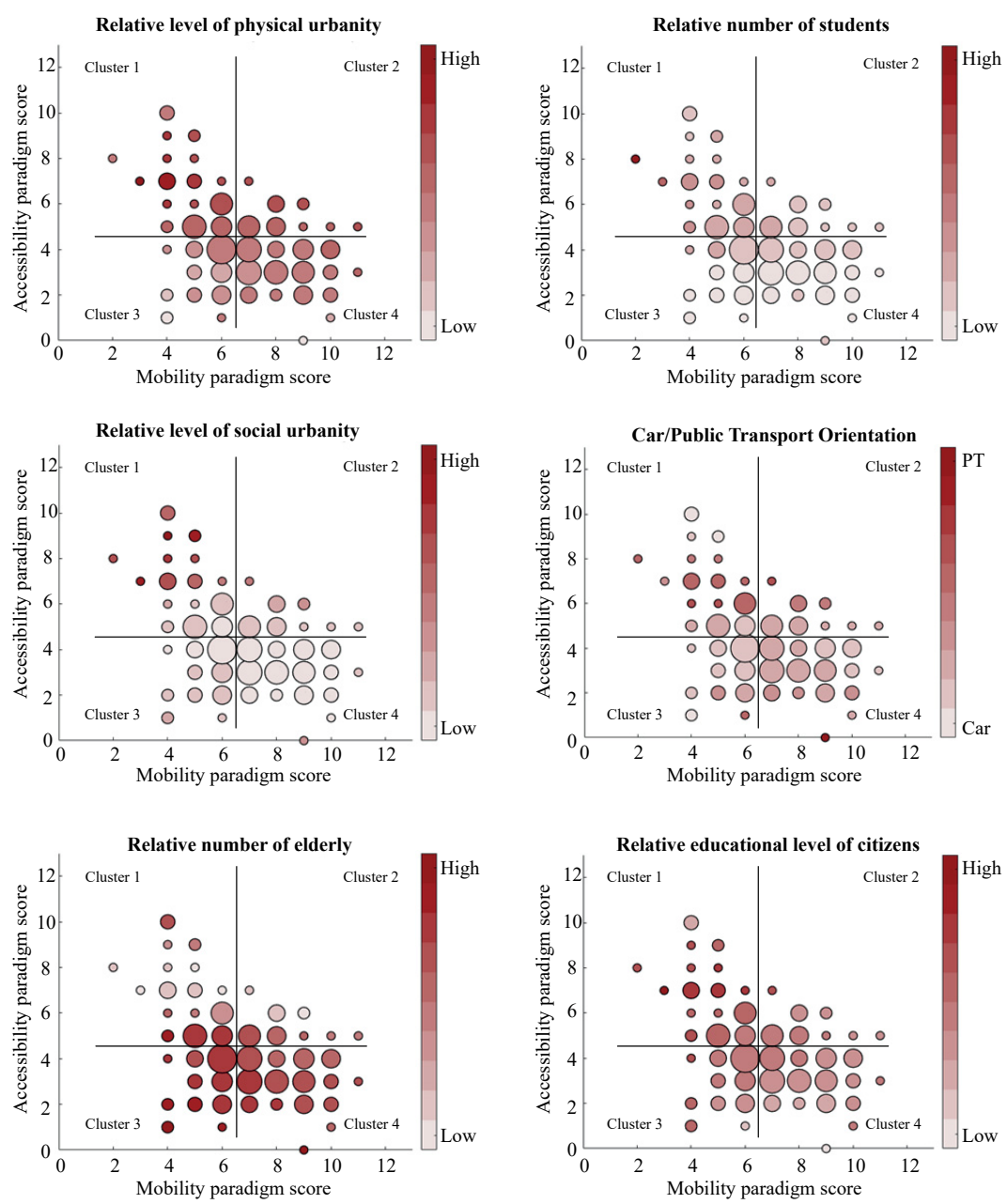

Figure 4. Component scores of components plotted as third dimension of policy document scores, using a moving average and four clusters

Generally, so-called frontrunners (i.e., municipalities scoring high on the accessibility planning paradigm and low on the mobility planning paradigm) are highly urban. There was a difference though between physical and social indicators. Frontrunner municipalities are large municipalities with high shares of low income, young and highly educated population groups. There were also some municipalities in the frontrunner quadrant which were not in line with the general trend of the six components. These municipalities were located in the south of the Netherlands (province of Limburg) with medium population densities, older population (high share of elderly, low share of students) and were more oriented towards car than public transport.

In order to show how all six components relate with the paradigm scores, a weighted multi-linear regression model was set up (displayed in Table 8) consisting of the balanced scores as the dependent variable and the component scores as independent variables. Models with the mobility score and the accessibility score as the dependent variable showed similar results in terms of significance and coefficients and were therefore not displayed. 
Table 8. Multiple weighted linear regression model $(\mathrm{R} 2=0.232)$

\begin{tabular}{|lccc|}
\hline Dependent variable: Balanced score & & & \\
\hline Variables & Coefficient & Beta & Significance (t-value) \\
\hline Constant & -2.599 & - & $0.000^{* * *}$ \\
\hline Physical urban character & 0.242 & 0.078 & 0.256 \\
\hline Number of students & 0.861 & 0.277 & $0.000^{* * *}$ \\
\hline Social urban character & 0.976 & 0.314 & $0.000^{* * *}$ \\
\hline Car/PT orientation & 0.158 & 0.051 & 0.458 \\
\hline Elderly citizens & 0.195 & 0.063 & 0.359 \\
\hline Educational level citizens & 0.658 & 0.212 & $0.002^{* *}$ \\
\hline $\begin{array}{l}* \text { Significant at 95\% confidence level }(\mathrm{p}<0.05) \\
\text { ** Significant at 99\% confidence level }(\mathrm{p}<0.01) \\
* * *\end{array}$ & & & \\
\hline
\end{tabular}

The results of this model indeed confirmed that physical urban character alone was not a good predictor for a high balanced score, as this variable was not significant in the model. Also the Car/PT orientation variable was not significant in the regression model, as well as the number of elderly citizens. The Social urban character component had the largest effect on the balanced score, followed by the number of students and the educational level of citizens. All in all, this meant that the component explaining the most variance of municipal characteristics (42.9\%) did not affect the balanced score in a uniform way. Frontrunner municipalities were highly urban in both a physical way and social way, but other municipalities having a low balanced score were also physically urban.

\subsection{Institutional and organizational characteristics}

For the organizational characteristics, only the year of publication, political orientation of the municipality and type of policy document (vision-based or GVVP-based) significantly differed for the four different clusters. Therefore, only these three variables were plotted along with the paradigm scores, using the convoluted values with the same kernel as in Figure 4. Also here, relative labels (mostly high/low) were used to improve interpretability.

Firstly, the type of document and the relative number of years functioning of the document are plotted in Figure 5.fThe frontrunner documents were the most recent in comparison with other municipal documents. Furthermore, frontrunner documents were written in the style of a mobility vision instead of a classic GVVP document. Combining these two plots implicated that more recent documents were more often written in the form of a mobility vision. The fact that younger documents had a higher balanced score, also indicates that there exists a learning curve from a mobility planning paradigm to an accessibility planning paradigm. Apparently, the form of a vision instead of a GVVP connects more with achieving this paradigmatic change. When reading all the documents, it did appear that vision-based documents had defined clearer policy goals and proposed a better integration of transport planning and spatial planning. Based on the literature, it was expected that an external consultancy presence would also be significantly different for explaining differences in balanced scores, as such a party could provide state-of-the-art knowledge with regard to mobility policies and planning. It appeared that this is not the case. We will come back to this point in the discussion. 

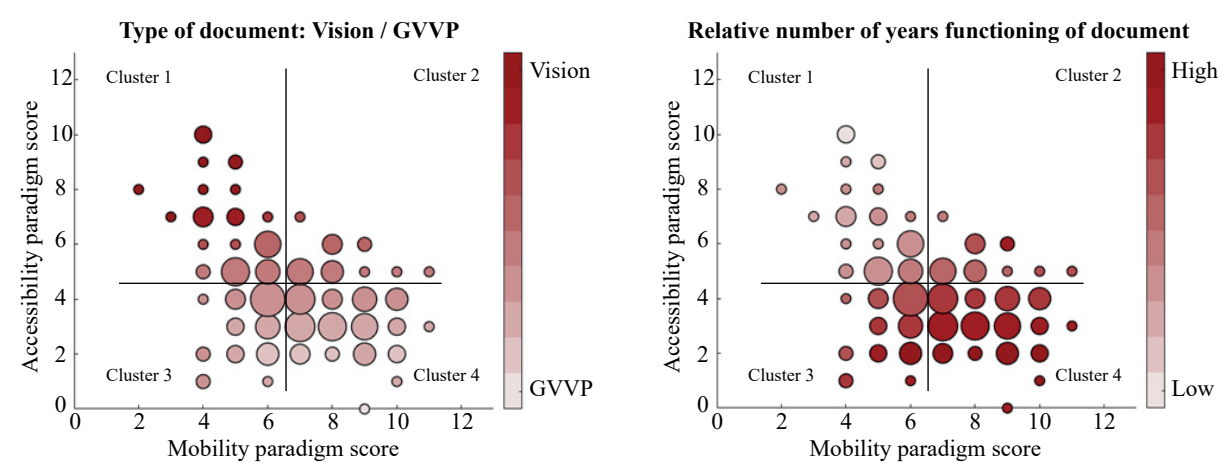

Figure 5. Organizational variables plotted as third dimension of policy document scores, using a moving average

This paper used the following block characterization of political parties in the Netherlands, which does right to the Dutch multi-party system (see Methodology): classic-right (VVD), progressive (D66, GL, PvdD), Confessional (CDA, CU, SGP), protest parties (PVV, FvD, 50PLUS, DENK) and classicleft (PvdA, SP). An analysis of the relative shares of political blocks in comparison with the policy document scores (as displayed in Figure 6) shows that the share of progressive parties correlates positively with the group of frontrunner municipalities. The classic-right party VVD, the block of confessional parties and block of protest parties correlated higher with the rest of the municipalities. All these correlations together indicate that the political orientation of a municipality does matter for the outcome of a policy document writing process. 

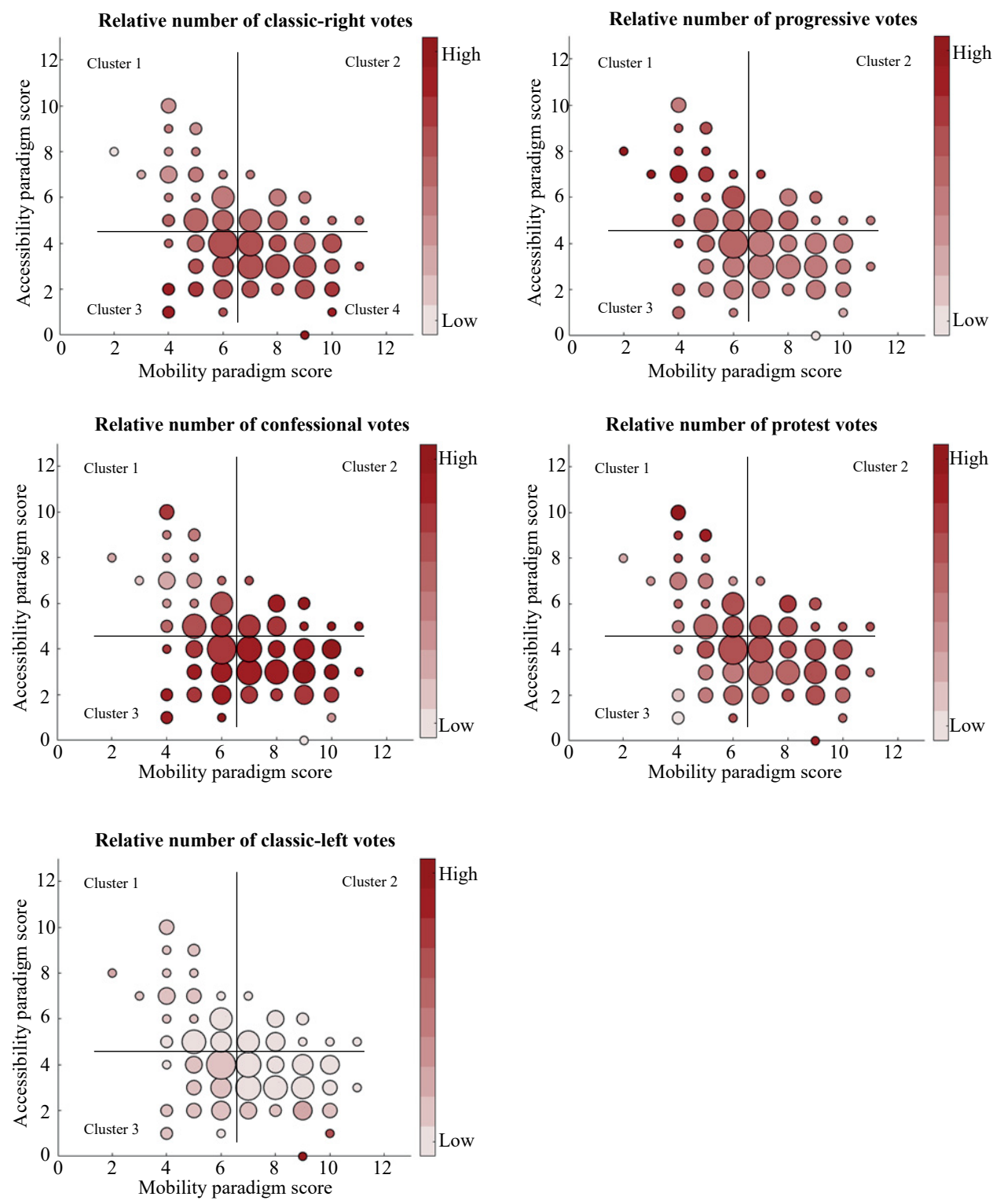

Figure 6. Relative share of political votes per block, plotted as a third dimension of policy document scores, using a moving average

Moreover, when reading through all the policy documents it was noticed that there was a subtle political difference in the language regarding modal choice preference, as displayed in Figure 7. One part of the documents explicitly chose for a policy prioritization of modes: active modes such as walking and cycling were considered as most important, then public transport, and least important the car. Practically, this meant that active modes were promoted in terms of space, travel times and financial budget. Car traveling was made less attractive through for example lower parking norms, less space for roads and so-called cuts in the network. Another considerable share of documents chose a very different approach however with regard to modal split. The basis of their thinking was choice of freedom: if all modes are at the same quality level, then travelers will automatically shift towards more sustainable modes. Many municipalities noticed that public transport and cycling networks were not at the same quality level as the car network is. Therefore, such policy documents stated that they aimed to invest in sustainable modes. 
At the same time however, car travel was not really discouraged because the traveler should have the possibility to make his or her own modal choice. Throughout the analysis of all the policy documents, a list was created independently of the scores with municipalities that adopt either modal prioritization or choice of freedom in their policies. Connecting the results of Figure 7 with Figure 6 shows that choice of freedom is adopted in mostly (liberal) right-wing and confessional municipalities. This makes sense, as these parties tend to be more in favor of having a free choice to travel by car. Municipalities that explicitly chose to prioritize active modes and deprioritize the car had a higher electoral share of progressive parties. These additional findings based on document analysis confirm the hypothesis that political values and choices indeed play a role in the policy process and eventually the establishment of a certain transport planning paradigm.

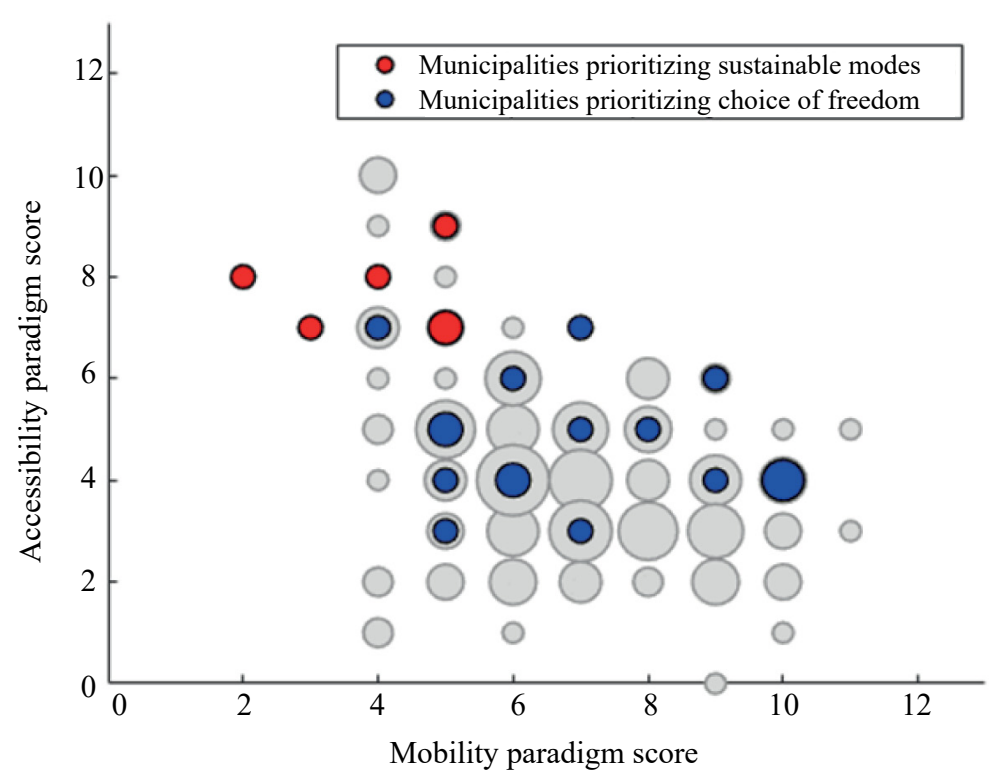

Figure 7. Two different types of political choices with regard to desired modal split

\section{Conclusions}

The aim of this paper was to operationalize the planning paradigm in an empirical context. To fulfill this objective, a conceptual framework was set up of criteria that described the mobility and accessibility planning paradigms. In doing so, a research gap was addressed of approaching transport planning and policies in a quantitative and coherent way, beyond traditional literature reviews.

A quantitative analysis of 172 Dutch municipal transport policy documents showed that most urban municipalities in the Netherlands adopt the mobility planning paradigm in their policies. The larger municipalities, highly urbanized with relatively young and low-income populations score high on the accessibility planning paradigm and low on the mobility planning paradigm (frontrunners). Physical urban character however does not correlate uniformly with paradigm scores as the organizational and institutional characteristics of municipalities also play a role and can form barriers towards the implementation of an accessibility planning paradigm. Furthermore, the year of publication, political orientation of the municipality and type of policy document are also found to influence the planning paradigm score. The older the document, the more likely that it was based on a mobility planning paradigm. This would imply that there is a slow shift happening from the mobility to the accessibility planning para- 
digm. The specific geographic pattern of progressive political parties concentrating in highly urban areas and the correlated adoption of the accessibility planning paradigm in such areas confirms the hypothesis of political values being important for the establishment of planning paradigms. Another outcome of this paper is that the link between the overall score of the planning paradigm and the action-based part is stronger than the relation with the idea/vision-based part.

\section{Discussion and directions for further research}

It is of course possible to propose different criteria for each planning paradigm, like modelling transit flows and cycling in a quantitative way, or applying a spatial analysis for car traveling. A limited sensitivity analysis shows though that there is a positive correlation of 0.59 between the balanced score of the cognitive elements and the balanced score of the action-based elements. This makes clear that choosing different criteria does not fundamentally change the results and the interpretation proposed in this paper. Still, empirical scores indicate that many municipalities cannot be put under one label in terms of planning paradigms: There exists in fact a large grey area between the two extremes. The planning paradigm concept as applied in practice is in this sense more fluid and contextual, rather than pointing towards the extremes. A more fundamental limit of document analysis is the question of what the actual operational status of the document in the local policy making process is. Is the plan truthfully written down on paper or in fact leading for local planning? A limited amount of interviews with policy makers in frontrunner municipalities, focusing on institutional conditions for paradigm change, confirm the existence of a gap between the goals written down on paper and making choices in the 'real' world. The results of these interviews will be shared in a future paper.

The results of this paper indicate that there is a slow change in transport planning paradigms happening in Dutch municipalities, but further research is necessary to confirm this shift (Handy, 2020). Interviewees furthermore suggest that the organizational aspects of a planning paradigm have great influence on the paradigmatic change. Especially the knowledge basis of policy makers and political triggers enable to move from a mobility planning paradigm to an accessibility planning paradigm, in line with insights as to why policy makers do or do not use accessibility instruments in planning (Boisjoly $\&$ El-Geneidy, 2017). It is not the case though that changes are always constructed in a deliberate way, or that there exists one blueprint for adopting integrative policy instruments (van Geet et al., 2021). Interviewees also mentioned that coincidence and accidental circumstances had helped in the writing of a renewed policy document. Policy makers indicated that their problem scope broadened through meeting new actors and incorporating them in the policy process, in line with Marsden et al. (2011). The presence of an external consultant did not correlate with higher or lower paradigm scores, even though some Dutch consultants have been active in developing accessibility instruments and promoting its use in the planning practice (e.g., Straatemeier \& Bertolini, 2019). However, the commercial aspect of consulting and consultants might be a barrier towards pushing accessibility-based approaches. On the other hand, municipalities which already have a broader view on mobility also choose a consultant which can help build a different mobility vision.

There are several future research possibilities that have come up in this paper. Firstly, more work is necessary to confirm the idea that paradigmatic policy change is happening in Dutch municipalities and if so, why. One line of quantitative research could be to compare the scores of the most recent municipal policy document with earlier versions, including a comparison of municipal funding. A qualitative line of research could look into extending the number of interviews around a selection of municipalities, to look into conditions that have triggered possible paradigm change.

Secondly, more work is necessary to define methodologies and programs to improve planning 
for all municipalities. Larger municipalities can rely on both a bigger social network and have more money to get external help. There is a division of winners and losers in the planning field, exemplified by knowledge, money and network capacities. The question is how (regional) networks can be built that also support smaller municipalities in developing a progressive policy plan. Furthermore, it might be interesting to differentiate between quality levels of criteria, for example in the case of cycling policies in the Netherlands (Harms et al., 2015). In other contexts though, different differentiation typologies might come up like issues of depopulation and lower levels of service in a rural area. Planning paradigms could also be applied in a non-western context, like cities of the Global South.

Finally, cooperation between academia and other societal institutions should be encouraged, see e.g., Caniglia et al. (2020). Policy makers are looking for new theoretical narratives and frameworks to build policies on. The distribution of academic knowledge to policy makers by actors who have an intermediary position between the practical policy making world and the theoretical academic world is therefore essential for future progressive transport planning (Kivimaa et al., 2019). 


\section{References}

Annema, J. A., Koopmans, C., \& Van Wee, B. (2007). Evaluating transport infrastructure investments: The Dutch experience with a standardized approach. Transport Reviews, 27(2), 125-150. https:// doi:10.1080/01441640600843237

Banister, D. (2008). The sustainable mobility paradigm. Transport Policy, 15(2), 73-80. https:// doi:10.1016/j.tranpol.2007.10.005

Banister, D. (2011). The trilogy of distance, speed and time. Journal of Transport Geography, 19(4), 950-959. https;//doi:10.1016/j.jtrangeo.2010.12.004

Boisjoly, G., \& El-Geneidy, A. M. (2017). The insider: A planners' perspective on accessibility. Journal of Transport Geography, 64, 33-43. https://doi:10.1016/j.jtrangeo.2017.08.006

Caniglia, G., Luederitz, C., von Wirth, T., Fazey, I., Martín-López, B., Hondrila, K., . . . Lang, D. J. (2020). A pluralistic and integrated approach to action-oriented knowledge for sustainability. Nature Sustainability, 4, 93-100. https://doi:10.1038/s41893-020-00616-z

Cervero, R. (1997). Paradigm shift: From automobility to accessibility planning. Urban Futures, 22(6), 9-20.

Dijst, M., Rietveld, P., \& Steg, L. (2013). Individual needs and travel behavior. In B. van Wee, J. A. Annema, \& D. Banister (Eds.), The transport system and transport policy: An introduction (pp. 19-50). Cheltenham, Northampton: Edward Elgar.

Ferreira, A., Beukers, E., \& Te Brömmelstroet, M. (2012). Accessibility is gold, mobility is not: A proposal for the improvement of Dutch transport-related cost-benefit analysis. Environment and Planning B: Planning and Design, 39(4), 683-697. https://doi:10.1068/b38073

Field, A. (2009). Discovering statistics using SPSS. London: SAGE Publications Ltd.

Geels, F. W. (2012). A socio-technical analysis of low-carbon transitions: Introducing the multi-level perspective into transport studies. Journal of Transport Geography, 24, 471-482. https://doi:10.1016/j. jtrangeo.2012.01.021

Geurs, K. T., \& Levine, J. (2015). Mind the gap: Barriers to the use of accessibility instruments. Paper presented at the NECTAR International Conference, June 14-16, Ann Arbor, MI.

Geurs, K. T., Zondag, B., de Jong, G., \& de Bok, M. (2010). Accessibility appraisal of land-use/transport policy strategies: More than just adding up travel-time savings. Transportation Research Part D: Transport and Environment, 15(7), 382-393. https://doi:10.1016/j.trd.2010.04.006

Hall, P. A. (1993). Policy paradigms, social learning, and the state: The case of economic policy making in Britain. Comparative Politics, 25(3), 275-296. https://doi:10.2307/422246

Handy, S. (2020). Is accessibility an idea whose time has finally come? Transportation Research Part D: Transport and Environment, 83, 102319. https://doi:10.1016/j.trd.2020.102319

Harbers, A., Spoon, M., van Amsterdam, H., \& van der Schult, J. (2019). Ruimtelijke dichtheden en functiemenging in Nederland (RUDIFUN). Den Haag: PBL

Harms, L., Bertolini, L., \& Brömmelstroet, M. T. (2015). Performance of municipal cycling policies in medium-sized cities in the Netherlands since 2000. Transport Reviews, 36(1), 134-162. https://doi: 10.1080/01441647.2015.1059380

Jensen, O. B. (2015). More than A to B: Cultures of mobilities and travel. In R. Hickman, M. Givoni, D. Bonilla, \& D. Banister (Eds.), Handbook on transport and development (pp. 479-490). Cheltenham, UK: Edward Elgar Publishing Limited.

Jones, P. (2012). The role of an evolving paradigm in shaping international transport research and policy agendas over the last 50 years. Paper presented at the 12th International Association for Travel Behavior Research in an Evolving World, December 13-18, Jaipur, India. 
Jones, P. (2014). The evolution of urban mobility: The interplay of academic and policy perspectives. IATSS Research, 38(1), 7-13. https://doi:10.1016/j.iatssr.2014.06.001

Kanger, L., Geels, F. W., Sovacool, B., \& Schot, J. (2019). Technological diffusion as a process of societal embedding: Lessons from historical automobile transitions for future electric mobility. Transportation Research Part D: Transport and Environment, 71, 47-66. https://doi:10.1016/j.trd.2018.11.012

Kivimaa, P., Boon, W., Hyysalo, S., \& Klerkx, L. (2019). Towards a typology of intermediaries in sustainability transitions: A systematic review and a research agenda. Research Policy, 48(4), 1062-1075. https://doi:10.1016/j.respol.2018.10.006

Koglin, T. (2015a). Organisation does matter - planning for cycling in Stockholm and Copenhagen. Transport Policy, 39, 55-62. https://doi:10.1016/j.tranpol.2015.02.003

Koglin, T. (2015b). Vélomobility and the politics of transport planning. GeoJournal, 80(4), 569-586. https://doi:10.1007/s10708-014-9565-7

Kuhn, T. (1962). The structure of scientific revolutions. Chicago: University of Chicago Press.

Levine, J., Grengs, J., \& Merlin, L. A. (2019). From mobility to accessibility: Transforming urban transportation and land-use planning. Ithaca: Cornell University Press.

Levine, J., Grengs, J., Shen, Q., \& Shen, Q. (2012). Does accessibility require density or speed? Journal of the American Planning Association, 78(2), 157-172. https://doi:10.1080/01944363.2012.677119

Litman, T. (2013). The new transportation planning paradigm. ITE Journal, 83(6), 20-28.

Lyons, G. (2018). Getting smart about urban mobility - Aligning the paradigms of smart and sustainable. Transportation Research Part A: Policy and Practice, 115, 4-14. https:/doi:10.1016/j. tra.2016.12.001

Marsden, G., Frick, K. T., May, A. D., \& Deakin, E. (2011). How do cities approach policy innovation and policy learning? A study of 30 policies in Northern Europe and North America. Transport Policy, 18(3), 501-512. https://doi:10.1016/j.tranpol.2010.10.006

Martens, K. (2017). Transport justice - Designing fair transportation systems. New York, USA: Routledge.

May, A. D. (2012). Urban transport and sustainability: The key challenges. International Journal of Sustainable Transportation, 7(3), 170-185. https://doi:10.1080/15568318.2013.710136

Norton, P. (2015). Four paradigms: Traffic safety in the twentieth-century United States. Technol Cult, 56(2), 319-334. https://doi:10.1353/tech.2015.0065

Papa, E., Silva, C., Te Brömmelstroet, M., \& Hull, A. (2015). Accessibility instruments for planning practice: A review of European experiences. Journal of Transport and Land Use, 9(3), 57-75. https:// doi:10.5198/jtlu.2015.585

Pritchard, J. P., Stępniak, M., \& Geurs, K. T. (2019). Equity analysis of dynamic bike-and-ride accessibility in the Netherlands. In K. Lucas, K. Martens, F. Di Ciommo, \& A. Dupont-Kieffer (Eds.), Measuring transport equity (pp. 73-83). Elsevier.

Rouse, J. (2003). Kuhn's philosophy of scientific practice. In T. Nickles (Ed.), Thomas Kuhn (pp. 101121). Cambridge: Cambridge University Press.

Schwanen, T., Banister, D., \& Anable, J. (2011). Scientific research about climate change mitigation in transport: A critical review. Transportation Research Part A: Policy and Practice, 45(10), 993-1006. https://doi:10.1016/j.tra.2011.09.005

Smaal, M. (2012). Politieke strijd om de prijs van automobiliteit: De geschiedenis van een langdurend discours: 1895-2010. Delft: Eburon.

Stone, J. (2013). Continuity and change in urban transport policy: Politics, institutions and actors in Melbourne and Vancouver since 1970. Planning Practice \& Research, 29(4), 388-404. https://doi:1 $0.1080 / 02697459.2013 .820041$

Stopher, P., \& Stanley, J. (2014). Introduction to transport policy - A public policy view. Cheltenham, UK: 
Edward Elgar.

Straatemeier, T., \& Bertolini, L. (2019). How can planning for accessibility lead to more integrated transport and land-use strategies? Two examples from the Netherlands. European Planning Studies, 1-22. https://doi: 10.1080/09654313.2019.1612326

SWOV. (2020, 15-04). Verkeersdoden in Nederland. SWOV-factsheet. Retrieved from https://www. swov.nl/feiten-cijfers/factsheet/verkeersdoden-nederland

Te Brömmelstroet, M., Silva, C., \& Bertolini, L. (2014). Assessing usability of accessibility instruments, COST Action TU1002. Brussels: COST Office

Tennøy, A., Hansson, L., Lissandrello, E., \& Næss, P. (2016). How planners' use and non-use of expert knowledge affect the goal achievement potential of plans: Experiences from strategic land-use and transport planning processes in three Scandinavian cities. Progress in Planning, 109, 1-32. htpps:// doi:10.1016/j.progress.2015.05.002

Van Der Brugge, R., Rotmans, J., \& Loorbach, D. (2005). The transition in Dutch water management. Regional Environmental Change, 5(4), 164-176. https://doi:10.1007/s10113-004-0086-7

van Geet, M. T., Lenferink, S., Busscher, T., \& Arts, J. (2021). Finding the right tools for the job: Instrument mixes for land use and transport integration in the Netherlands. Journal of Transport and Land Use, 14(1), 125-149. https://doi:10.5198/jtlu.2021.1710

van Wee, B., Banister, D., Annema, J. A., \& Geurs, K. T. (2013). Transport and the environment. In B. van Wee, J. A. Annema, \& D. Banister (Eds.), The transport system and transport policy: An introduction (pp. 227-253). Cheltenham, Northampton: Edward Elgar.

Van Wijk, D. (2019, 20-2). Een nieuwe manier om verkiezingsuitslagen in kaart te brengen in een versnipperd politiek landschap. Retrieved from http://stukroodvlees.nl/een-nieuwe-manier-om-verziekingsuitslagen-in-kaart-te-brengen-in-een-versnipperd-politiek-landschap/

von Schönfeld, K. C., \& Bertolini, L. (2017). Urban streets: Epitomes of planning challenges and opportunities at the interface of public space and mobility. Cities, 68, 48-55. https:/doi:10.1016/j. cities.2017.04.012

Wegman, F. (2013). Traffic safety. In B. van Wee, J. A. Annema, \& D. Banister (Eds.), The transport system and transport policy: An introduction (pp. 254-280). Cheltenham, Northampton: Edward Elgar.

Zhao, C., Carstensen, T. A., Nielsen, T. A. S., \& Olafsson, A. S. (2018). Bicycle-friendly infrastructure planning in Beijing and Copenhagen - between adapting design solutions and learning local planning cultures. Journal of Transport Geography, 68, 149-159. https://doi:10.1016/j.jtrangeo.2018.03.003 